\title{
Science and security for changing water quantity and quality with rapid urbanisation and variability in climate and society
}

\author{
ANAND VERDHEN \\ Dept. of Civil Engineering, Dronacharya College of Engineering, Khentawas, Gurgaon, India \\ anand indra3@yahoo.co.in
}

The water resources regime of the Himalyas has been in a phase of transition over the last 30 years. Figure 1 shows temperature and precipitation from 1978 to 2008 measured at a typical location, Bhang in the Pir-Panjal range of the Himalayas. There is a sign of rise in the seasonal mean temperature $\left(0.1^{\circ} \mathrm{C} /\right.$ year at Bhang $)$ and rise in the consumption of freshwater. The pattern of rainfall is variable and the Himalayan snow cover and snowmelt runoff contributions to the streams are changing due to warming (Verdhen et al. 2011). The change in precipitation and runoff is also related to deforestation and unscientific capital-intensive rapid development in the region over three decades (Verdhen and Prasad 1993, Arora et al. 2008). Human interference, trekking, tourism and mobility have multiplied the uncertainty related to the sustainability of the Himalayan water resources. Verdhen et al. (2014) used an average condition temperature-timemelt-flow (TTiMQ) regression model to reduce the prediction variability at the local scale.

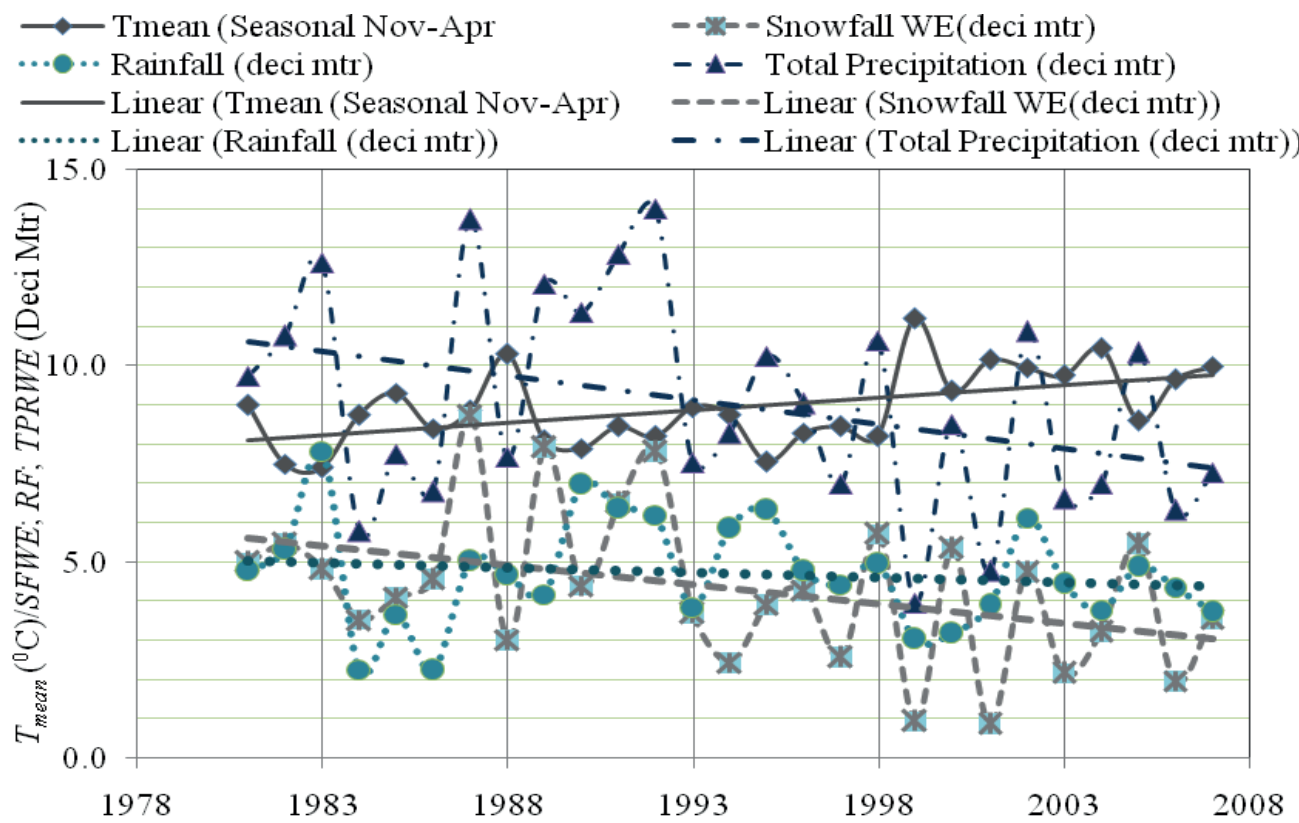

Fig. 1 Seasonal mean temperature $\left(T_{\text {mean }}\right)$, snowfall water equivalent $(S F W E)$, rainfall $(R F)$ and winter precipitation (TPRWE) at Bhang, which is located at Lat. $32^{\circ} 17^{\prime} \mathrm{N}$; Long. $77^{\circ} 12^{\prime} \mathrm{E}$ and $2192 \mathrm{~m}$ a.s.l. in the Pir-Panjal range of the Himalayas (after Verdhen 2013).

Over-exploitation of groundwater for drinking and assured irrigation have imposed negative impacts on the quality of groundwater resources. The groundwater reserve is depleting. The recharge area and scope of natural replenishment are shrinking due to urbanization and consequent paving of the land surface and encroachment on surface water bodies, i.e. ponds, ahars and ditches. Rapid urbanization demands unlimited water. Increased impervious zones due to urbanization diminish groundwater recharge leading to a reduced groundwater reserve. Delhi is a mega-city and the problems of groundwater quality and quantity are chronic. According to the Central Ground Water Board, the groundwater level has fallen by $8 \mathrm{~m}$ in Delhi. The natural recharge is almost negligible due to the limited periods of rainfall and paved ground surfaces. Rooftop rainwater 
harvesting and artificial recharge are important and are the policy of the Government which advocates water conservation (Verdhen et al. 2007). The Government has been providing subsidies to promote rooftop harvesting-cum-artificial recharge, if the plot-size exceeds a particular limit. However, a positive impact has yet to be realised. Moreover, the groundwater is becoming contaminated by such artificial recharge and is no longer fresh enough for drinking without treatment. The Delhi Jal Board (DJB) has projected the decadal water requirement and wastewater generation as 8365 MLD $\left(10^{6} \mathrm{~L} \mathrm{~d}^{-1}\right)$ and $6692 \mathrm{MLD}$, respectively during 2021 (CPCB 2004). The reasons behind the incremental and absolute falling of the water table or piezometric head, apart from over-exploitation, seems to be interlinking of confined and unconfined aquifers through deep tube wells. This new concept can be known as Verdhen's Principle of Groundwater Head Balance. The matter is of great concern for the sustainability of groundwater potential and the livelihood of mankind.

The rate and volume of sewage production is increasing enormously from the source to outfall of water bodies (stored or flowing). During the non-monsoon and lean-flow periods, the pollution load and de-oxygenation are so high that streams normally having self-cleaning properties by natural processes and dilution, become intolerable foul emitters. Treatment plants are unreliable and are not optimally designed to treat either low-flows in sewer lines exclusively, or high-flows due to storm-drain water mixing. The centralized wastewater treatment has proven to be just an "eye-wash" and unsatisfactory. Overall, the quantity, distribution and quality of natural waters are at stake. Freshwater misuse and the freshwater market have become a competitive fashion involving flushing, tub-baths, swimming pools, vehicle washing, cooling fountains, and watering kitchen gardens and grass/flower beds in parks, etc. The study aims to develop region specific suitable strategies with following major actions for effective and sustainable water resources:

(a) Study and investigations into change in society and its priority, as well as the state-of-the-art of science and technology to meet the emerging challenges of the future.

(b) Improvements in simulation and hydrological modelling for operational purposes.

(c) Issues related to climate change and hydrological variability at regional scale for awareness, adaptation and impact mitigation measures.

(d) Issues related to fresh and sustainable water supply and conservation for urban populations.

(e) Cost-effective and risk-free strategy of sewage disposal, treatment, recycling and utilization.

(f) Optimization and management of water quantity and quality in vulnerable areas.

(g) Water security for the future, based on experience (Cisneros and Rose 2009).

(h) Water resources integrated management including aims of the Global Water Partnerships.

\section{REFERENCES}

Arora, M., et al. (2008) Climate variability influences on hydrological responses in a large Himalayan Basin. Water Resour Manage 22, 1461-1475.

Cisneros, B.J. and Rose J.B. (2009) Urban Water Security: Managing Risks. Urban Water Series - UNESCO-IHP. UNESCOIHP, ISBN-10: 0415485665, Taylor \& Francis.

CPCB (2004) Status of sewerage and sewage treatment plants in Delhi. Control of Urban Pollution Series (CUPS). Central Pollution Control Board, Parivesh Bhawan, East Arjun Nagar, Delhi, India.

Verdhen, A. (2007) Process, planning and design of water conservation. In: Proc. of Seminar on Water Resources Day: Water Conservation, Institution of Engineers, Assam State Center, Guwahati, India.

Verdhen, A. (2013) Snow and glacier melt simulation for hydrology in a typical Himalayan watershed. PhD Thesis, Indian Institute of Technology Delhi, New Delhi, India.

Verdhen, A. and Prasad, T. (1993) Snowmelt runoff simulation models and their suitability in Himalayan conditions. In: J. G. Young (ed.) Snow and Glacier Hydrology. IAHS Publ. 218, 239-248.

Verdhen, A., Chahar, B. and Sharma, O.P. (2011) Climate change impact on snow and glacier hydrology simulation of a Himalayan watershed. In: Proc. of International Perspective on Water and Environment, IPWE-2011, Singapore.

Verdhen, A., Chahar, B.R. and Sharma, O.P. (2014) Springtime snowmelt and streamflow predictions in the Himalayan Mountains. J. Hydrol Engrg. 19(7), 1452-1461, doi: 10.1061/(ASCE)HE.1943-5584.0000816 